\title{
Snapshot: Talking Statistics/Talking Ourselves: Some Constructionist Lessons from the Work of the Psychologist George Kelly-James Clayson
}

\author{
Uri Wilensky
}

Published online: 13 October 2013

(C) Springer Science+Business Media Dordrecht 2013

In this snapshot, James Clayson, describes a computational tool he developed, inspired by the psychology of George Kelly, that mines people's personal relationships for statistical analysis, thereby exciting non-mathematicians to talk about statistics.

This column will publish short (from just a few paragraphs to ten or so pages), lively and intriguing computer-related mathematics vignettes. These vignettes or snapshots should illustrate ways in which computer environments have transformed the practice of mathematics or mathematics pedagogy. They could also include puzzles or brain-teasers involving the use of computers or computational theory. Snapshots are subject to peer review. From the Column Editor, Uri Wilensky, Northwestern University, e-mail: uri@northwestern.edu.

U. Wilensky $(\square)$

Northwestern University, Evanston, IL, USA

e-mail: uri@northwestern.edu 